\title{
BMJ Open The pathway to diagnosis of type 1 diabetes in children: a questionnaire study
}

\author{
Juliet A Usher-Smith, ${ }^{1}$ Matthew J Thompson, ${ }^{2}$ Hannah Zhu, ${ }^{3}$ Stephen J Sharp, ${ }^{4}$ \\ Fiona $\mathrm{M} \mathrm{Walter}^{1}$
}

To cite: Usher-Smith JA, Thompson MJ, Zhu H, et al. The pathway to diagnosis of type 1 diabetes in children: a questionnaire study. BMJ Open 2015;5:e006470. doi:10.1136/bmjopen-2014006470

- Prepublication history and additional material is available. To view please visit the journal (http://dx.doi.org/ 10.1136/bmjopen-2014006470).

Received 26 August 2014 Revised 17 November 2014 Accepted 20 November 2014

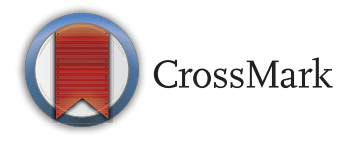

For numbered affiliations see end of article.

Correspondence to Dr Juliet A Usher-Smith; jau20@medschl.cam.ac.uk

\section{ABSTRACT}

Objective: To explore the pathway to diagnosis of type 1 diabetes (T1D) in children.

Design: Questionnaire completed by parents.

Participants: Parents of children aged 1 month to 16 years diagnosed with T1D within the previous 3 months.

Setting: Children and parents from 11 hospitals within the East of England.

Results: 88/164 (54\%) invited families returned the questionnaire. Children had mean $\pm \mathrm{SD}$ age of 9.41 \pm 4.5 years. $35(39.8 \%)$ presented with diabetic ketoacidosis at diagnosis. The most common symptoms were polydipsia $(97.7 \%)$, polyuria $(83.9 \%)$, tiredness $(75.9 \%)$, nocturia $(73.6 \%)$ and weight loss $(64.4 \%)$ and all children presented with at least one of those symptoms. The time from symptom onset to diagnosis ranged from 2 to 315 days (median 25 days). Most of this was the appraisal interval from symptom onset until perceiving the need to seek medical advice. Access to healthcare was good but one in five children presenting to primary care were not diagnosed at first encounter, most commonly due to waiting for fasting blood tests or alternative diagnoses. Children diagnosed at first consultation had a shorter duration of symptoms $(p=0.022)$ and children whose parents suspected the diagnosis were 1.3 times more likely (relative risk (RR) $1.3,95 \% \mathrm{Cl} 1.02$ to 1.67 ) to be diagnosed at first consultation.

Conclusions: Children present with the known symptoms of T1D but there is considerable scope to improve the diagnostic pathway. Future interventions targeted at parents need to address the tendency of parents to find alternative explanations for symptoms and the perceived barriers to access, in addition to symptom awareness.

\section{INTRODUCTION}

Approximately 65000 children are diagnosed with type 1 diabetes (T1D) each year and the incidence is continuing to increase at a rate of approximately $3 \%$ per year. $^{1}{ }^{2}$ The most common symptoms are well described and include polyuria, polydipsia, weight loss and tiredness. At the early stages of the disease, however, these symptoms are often non-

\section{Strengths and limitations of this study}

- This study uses a questionnaire developed from a previous interview study to explore the diagnostic pathway of children with newly diagnosed type 1 diabetes.

- It uses the Model of Pathway to Treatment as a framework to allow analysis of the factors acting at different stages in the pathway.

- The inclusion of a calendar with key events in the questionnaires and use of free text responses for internal validation and checking of prompted responses reduced bias but the data was necessarily collected retrospectively and so are subject to recall and framing bias.

specific and distinguishing the children with T1D from the large number with similar symptoms and minor undifferentiated illness can therefore be difficult. This is reflected in studies which have shown that the mean duration of symptoms prior to diagnosis is over 2 weeks with a significant number of children experiencing delay in diagnosis or misdiagnosis ${ }^{3}$ and only one in five diagnosed at first encounter. ${ }^{4-8}$ Up to $80 \%$ of children additionally present in diabetic ketoacidosis (DKA), ${ }^{9}$ which has immediate life-threatening complications and is associated with poorer long-term diabetic control. ${ }^{10-12}$

While several studies have highlighted these difficulties in making the diagnosis and the features associated with diabetic ketoacidosis at diagnosis, ${ }^{3-8} 13$ few have explored the period between symptom onset and diagnosis. Our recent qualitative interview study of parents and general practitioners (GPs) of children newly diagnosed with T1D suggested that the longest component in the diagnostic pathway is the time between onset of symptoms and the decision to seek medical help (known as the appraisal interval). ${ }^{14}$ The early symptoms are subtle, and even with some knowledge of T1D it took many parents several weeks of a complex decision-making process and often a 
physical trigger, such as weight loss or vomiting, to decide to consult a healthcare professional. Once the decision to seek help had been made almost all children were seen immediately and diagnoses were mostly prompt and managed appropriately. Parents continued to play a key role during the diagnostic interval however, with many having already made or suspected the diagnosis themselves, and several feeling that their GP did not take their concerns seriously.

This study builds on this earlier work by using a questionnaire developed from the interview findings to further explore the pathway to diagnosis of T1D in children. By using a structured questionnaire to survey a larger number of families we aimed to quantify the symptoms and their time course prior to diagnosis, the triggers and barriers to seeking help, the influence of parental prior knowledge of diabetes and the role of healthcare services.

\section{METHODS}

Design

A questionnaire about the pathway from first symptom (s) to diagnosis was completed by the parent(s)/guardian(s)/step-parents (hereafter referred to as parents) of children aged 1 month to 16 years diagnosed with T1D within the previous 3 months.

\section{Recruitment}

Children and parents were identified and recruited via the paediatric diabetes specialist nurses and research nurses at 11 hospitals within the East of England Diabetes Children and Young People's Network. Parents of all children aged 1 month to 16 years who were diagnosed with T1D within the previous 3 months at participating hospitals were eligible for inclusion unless their clinical team felt that this was not appropriate. Parents who failed to respond within 1 month were sent a reminder letter with a further copy of the questionnaire. Recruitment began at each site between February 2013 and April 2013, and continued across all sites until January 2014.

The clinical or research teams at all sites collected data on the age and gender of each child diagnosed during the study period and whether they had DKA at diagnosis. Each hospital used a slightly different definition of DKA but all included either $\mathrm{pH}<7.3$ or bicarbonate $<15 \mathrm{mmol} / \mathrm{L}$ (see online appendix table 1 ).

\section{The questionnaire}

The questionnaire was developed from the findings of our previous qualitative study of parents and children recently diagnosed with T1D. ${ }^{14}$ It was first reviewed by an expert panel comprising paediatric diabetes consultants, a paediatric diabetes research nurse and primary care researchers, and then piloted with parents of four children recently diagnosed with T1D. In addition to their specific feedback, parents were asked to talk aloud while completing the questionnaire and then interviewed after completion to ensure face validity. Based on feedback from the parents, the questionnaire was revised.
The final questionnaire included five sections (see online supplementary file). The first included questions about the child's age, gender, postcode, ethnic background, family history of diabetes, any medically trained family members and the number of children in the household. Parents were also asked if they knew what the symptoms of diabetes in children were before their child was diagnosed, and if so, to give details of those symptoms they were aware of. The second section asked about the symptoms the children had experienced with yes/no responses for 14 symptoms and space to add the date they noticed the symptoms, what they thought the symptoms were due to at the time and how much they concerned them. The third section focused on help-seeking and asked where parents had looked for information, who they spoke to and then details on when and how they had sought medical advice. It also asked them to describe their main concern at their first appointment and whether they had considered diabetes. Parents were also asked in this section about factors contributing to their decision to seek medical advice sooner or later. The fourth section asked about the diagnosis, including whether it was made at their first appointment with a healthcare professional and, if not, how many subsequent consultations they had, and the investigations that were performed before diagnosis. The final section then asked parents if they felt there was anything that prolonged them finding out their child had diabetes and had further space for free text comments.

\section{Analysis}

Data from the questionnaires were entered into a database and then double checked by a second researcher. Socioeconomic status was computed using postcode and the English indices of deprivation 2010 available online. ${ }^{15}$ The presence of DKA at diagnosis was obtained from hospital records rather than self-report. Walter et $a l$ s Model of Pathways to Treatment ${ }^{16}{ }^{17}$ provided a theoretic model of the intervals that occur prior to a diagnosis. This model divides the pathway to diagnosis into two intervals prior to presentation to healthcare about a symptom (the appraisal interval from the onset of symptoms to perceiving a reason to discuss symptoms with a healthcare professional, and the help-seeking interval from that decision until presentation to a healthcare professional), and then the diagnostic interval from first presentation to a healthcare professional until diagnosis. The help-seeking interval was further subdivided into the behavioural interval (the time between perceiving the reason to discuss the symptoms with a healthcare professional to making the decision to seek help) and the scheduling interval (the time between making the decision to seek help and the first consultation). ${ }^{18}$ Intervals were calculated from responses to the questionnaire. Where dates were incomplete we applied midpoint rules to estimate the actual date. ${ }^{19}$ In cases where the responses in free text differed from the dates entered as numbers, the free text was assumed to be correct, and where there was uncertainty the researchers met to agree consensus. 
Characteristics (age, gender, presence of DKA) were compared between children whose parents had and had not returned a questionnaire using a $t$ test for age and $\chi^{2}$ test for gender and presence of DKA. All further analyses used only data from returned questionnaires. The frequency of the 14 symptoms was compared between those with and without DKA using a $\chi^{2}$ test. Cox regression was used to estimate the association between various factors and the hazard of diagnosis; if a factor was associated with an increased hazard (ie, HR greater than 1), this implied that that factor was associated with a shorter time to diagnosis, and vice versa. Time to diagnosis was from the date of the earliest symptom to the date of diagnosis, and the factors assessed were age, gender, family history of T1D, index of multiple deprivation, prior knowledge of symptoms of T1D, whether the parents suspected $\mathrm{T} 1 \mathrm{D}$, whether the diagnosis was made at the first consultation, whether the first consultation was with primary or secondary care and whether the child had DKA at diagnosis. A similar approach was used to assess factors associated with the length of the appraisal and help-seeking intervals (with the end of the interval being defined as the 'event' in the Cox model), but only the first six variables in the list above were considered, as the others do not relate to those time intervals. The Schoenfeld residuals test was used to assess the proportional hazards $(\mathrm{PH})$ assumption for each covariate in each model. Whether parents suspected the diagnosis of T1D did not meet the PH assumption for the total diagnostic interval and so the Cox regression model was stratified by that variable. Logistic regression was used to estimate the association between the same factors and presence of DKA at diagnosis. All analyses were performed using STATAV.12.

Free text responses were grouped into similar categories and coded. Where individual free text responses contained several comments, these were each coded individually.

\section{RESULTS}

A total of 172 children were diagnosed with T1D in the 11 hospitals during the study period. Of those, eight families were not invited to take part in the study: five lived outside the hospital catchment area; one emigrated the week after diagnosis; and the clinical team felt it was not appropriate to include two. From the remaining 164 families invited to take part in the study, 88 (54\%) completed and returned the questionnaire. There were no significant differences in the proportion presenting in DKA $(p=0.27)$, mean age $(p=0.77)$ or gender $(p=0.77)$ between children of responders and non-responders.

One child was excluded from the analysis as they had no symptoms and the diagnosis was made on a random blood glucose test that the parents were doing at home on an intermittent basis as they had an older child with T1D. Children whose parents checked blood glucose at home after noticing symptoms remain in the analysis. Eighty-seven children are therefore included in the analysis that follows.
Table 1 shows the characteristics of the 87 children and families included in the study. The mean age was $9.34 \pm 4.5$ years, $49(56.3 \%)$ were male and $35(40.2 \%)$ presented with DKA at diagnosis. The majority (90.8\%) were white and as a group they were generally from less deprived areas of England, with $49.4 \%$ from the least deprived tertile of English Indices of Deprivation and only $10.3 \%$ from the most deprived.

\section{Symptoms}

Table 2 shows the frequency and duration of the 14 symptoms that were specifically asked about in the questionnaire. The most common symptoms were polydipsia $(97.7 \%)$, polyuria $(83.9 \%)$, tiredness $(75.9 \%)$, nocturia $(73.6 \%)$ and weight loss $(64.4 \%)$. Most symptoms were present for a median of between 13 and 17 days. Faster breathing and vomiting both had much shorter median (IQR) durations of $0.5(0-7.5)$ and $2.5(1.5-5.5)$ days respectively than the other symptoms. Weight loss, vomiting and faster breathing were significantly more frequent in those children who presented in DKA ( $p=0.014,<0.0005$ and 0.001 , respectively). All the children had at least one of the four main symptoms

\begin{tabular}{|c|c|c|}
\hline Child and family characteristics & Number & Percentage \\
\hline \multicolumn{3}{|l|}{ Gender } \\
\hline Male & 49 & 56.3 \\
\hline Female & 38 & 43.7 \\
\hline \multicolumn{3}{|l|}{ Age } \\
\hline $0-5$ & 26 & 29.9 \\
\hline $6-10$ & 20 & 23.0 \\
\hline $11-16$ & 41 & 47.1 \\
\hline Mean \pm SD & $9.34 \pm 4.5$ & \\
\hline \multicolumn{3}{|l|}{ Ethnicity } \\
\hline White & 79 & 90.8 \\
\hline Asian & 2 & 2.3 \\
\hline Black & 3 & 3.4 \\
\hline Mixed & 3 & 3.4 \\
\hline \multicolumn{3}{|l|}{ Family history } \\
\hline $\begin{array}{l}\text { First degree relative(s) } \\
\text { with T1D }\end{array}$ & 7 & 8.0 \\
\hline First degree relative(s) with T2D & 8 & 9.2 \\
\hline $\begin{array}{l}\text { Second or third degree } \\
\text { relative(s) with T1D }\end{array}$ & 13 & 14.9 \\
\hline $\begin{array}{l}\text { Second or third degree } \\
\text { relative(s) with T2D }\end{array}$ & 24 & 27.6 \\
\hline \multicolumn{3}{|l|}{ Indices of deprivation } \\
\hline Least deprived tertile & 43 & 49.4 \\
\hline Middle tertile & 33 & 37.9 \\
\hline Most deprived tertile & 9 & 10.3 \\
\hline Missing & 2 & 2.3 \\
\hline Medically trained family member & 9 & 10.3 \\
\hline \multicolumn{3}{|l|}{ DKA at diagnosis } \\
\hline Yes & 35 & 40.2 \\
\hline No & 52 & 60.0 \\
\hline
\end{tabular}


Table 2 Frequency of symptoms among all children and those with and without diabetic ketoacidosis (DKA) and duration of individual symptoms

\begin{tabular}{|c|c|c|c|c|c|c|c|c|c|}
\hline & \multicolumn{6}{|c|}{ Frequency of symptoms } & \multicolumn{3}{|c|}{ Duration of symptoms } \\
\hline & \multicolumn{2}{|c|}{ All $(n=87)$} & \multicolumn{2}{|c|}{ DKA $(n=35)$} & \multicolumn{2}{|c|}{ No-DKA $(n=52)$} & \multirow[b]{2}{*}{ Mean \pm SD } & \multirow[b]{2}{*}{ Median (IQR) } & \multirow[b]{2}{*}{$\mathbf{n}$} \\
\hline & $\mathrm{n}$ & Per cent & $\mathrm{n}$ & Per cent & $\mathrm{n}$ & Per cent & & & \\
\hline Polydipsia & 85 & 97.7 & 33 & 94.3 & 52 & 100 & $31.9 \pm 48$ & $16(8,36)$ & 77 \\
\hline Polyuria & 73 & 83.9 & 27 & 77.1 & 46 & 88.5 & $29.8 \pm 53$ & $14(5,26)$ & 65 \\
\hline Tiredness & 66 & 75.9 & 28 & 80.0 & 38 & 73.1 & $34.5 \pm 49.2$ & $17(10,39)$ & 53 \\
\hline Nocturia & 64 & 73.6 & 28 & 80.0 & 36 & 69.2 & $31.3 \pm 52.1$ & $15.5(7,28.5)$ & 56 \\
\hline Weight loss & 56 & 64.4 & 28 & $80.0^{*}$ & 28 & $53.8^{*}$ & $50.1 \pm 82.7$ & $13.5(7,44)$ & 42 \\
\hline Changes in behaviour/mood & 48 & 55.2 & 17 & 48.6 & 31 & 59.6 & $34.3 \pm 40.8$ & $15(8,42)$ & 34 \\
\hline Change in appetite & 45 & 51.7 & 18 & 51.4 & 27 & 51.9 & $30.7 \pm 48$ & $14.5(7,39)$ & 38 \\
\hline Abdominal pain & 37 & 42.5 & 17 & 48.6 & 20 & 38.5 & $41.4 \pm 64.1$ & $17(7,38)$ & 25 \\
\hline Noctural enuresis & 33 & 37.9 & 14 & 40.0 & 19 & 36.5 & $28.4 \pm 49.2$ & $15(5.5,21.5)$ & 28 \\
\hline Different smelling breath & 31 & 35.6 & 14 & 40.0 & 17 & 32.7 & $17.5 \pm 28.7$ & $6.5(3,17)$ & 22 \\
\hline Vomiting & 17 & 19.5 & 15 & $42.9^{*}$ & 2 & $3.8^{*}$ & $7.3 \pm 12.6$ & $2.5(1.5,5.5)$ & 8 \\
\hline Faster breathing & 15 & 17.2 & 12 & $34.3^{*}$ & 3 & $5.8^{*}$ & $3.8 \pm 5.8$ & $0.5(0,7.5)$ & 8 \\
\hline Urinary incontinence & 14 & 16.1 & 4 & 11.4 & 10 & 19.2 & $36.6 \pm 77.2$ & $10(3,21)$ & 10 \\
\hline Fever & 12 & 13.8 & 6 & 17.1 & 6 & 11.5 & $25 \pm 35.8$ & $8(2,55)$ & 7 \\
\hline
\end{tabular}

(polydipsia, polyuria or nocturia, weight loss, or tiredness), $97.7 \%$ had two or more, $79.3 \%$ three or more and over half $(50.6 \%)$ had all four symptoms.

A small number of parents mentioned symptoms other than those listed in the questionnaire, these included constipation (9), headaches (3), thrush (3), blurred vision (2), dry skin (2) and different smelling urine (1).

\section{Diagnostic intervals}

Table 3 shows the mean \pm SD and median (IQR) for the diagnostic intervals. Additional details on the diagnostic intervals for different subgroups are shown in online supplementary appendix table 2 . The total diagnostic interval ranged from 2 to 315 days with a median (IQR) of 25 days (14-50). In unadjusted Cox regression analysis (data not shown) the time to diagnosis was significantly shorter for children diagnosed at first appointment compared with a subsequent appointment $(p=0.046)$ and for those seen in secondary care rather than primary care $(\mathrm{p}=0.01)$. No evidence of associations with time to diagnosis was found for age, gender, family history of T1D, deprivation, prior knowledge of symptoms or DKA at diagnosis. In multivariable cox regression including age, gender, family history of T1D, index of multiple deprivation, prior knowledge of symptoms of T1D, whether the diagnosis was made at the first consultation, whether the first consultation was with primary or secondary care and whether the child had DKA at diagnosis (figure 1A), the association between whether the diagnosis of T1D was made at the first or subsequent appointments and total diagnostic interval remained statistically significant $(p=0.022)$.

\section{The appraisal interval}

The appraisal interval was the longest of all the intervals in the pathway for all but three of the families with a mean $\pm \mathrm{SD}$ of $41.0 \pm 51.7$ days and median (IQR) 20 (9-40) days.
During this period nearly two-thirds $(64 \%)$ of parents discussed the symptoms with family members, $40 \%$ with friends and $41 \%$ looked on the internet. Only $16 \%$ spoke to the child's nursery, school or playgroup and very few (6\%) looked for information in books. Over half of parents $(49,56 \%)$ reported being aware of some symptoms of T1D in children prior to their child's diagnosis: 40 $(45 \%)$ were aware of increased thirst, $24(27 \%)$ of polyuria, $17(19 \%)$ of weight loss and $13(15 \%)$ tiredness.

Cox-regression analysis (figure $1 \mathrm{~B}$ ) showed no significant associations between parent/child characteristics and the appraisal interval.

Analysis of the free text showed that most parents found explanations for their child's symptoms (table 4). For example, polydipsia was attributed most commonly to hot weather $(19 / 58,33 \%)$ or infection $(13 / 58,22 \%)$, polyuria and nocturia were frequently explained by drinking more (29/47, 62\% and 26/40,65\%) and tiredness was thought to be school related (12/44, $27 \%)$ or secondary to infection $(5 / 44,12 \%)$ or nocturia $(4 / 44,10 \%)$.

The majority of parents $(61 / 87,70 \%)$ additionally reported that they had suspected diabetes before their first consultation with a healthcare professional. When asked what had made them suspect diabetes, the most common reason given was that they knew the symptoms $(22 / 59,37 \%)$, especially thirst $(12 / 59$, $20 \%)$. Others cited information from the internet $(12 / 59,20 \%)$ or having a family history of diabetes $(11 / 59,19 \%)$.

\section{The help-seeking interval}

Twenty-four $(28 \%)$ children were seen on the same day their parents first thought about seeking medical advice and $64(74 \%)$ within 5 days. Most of this time was the behavioural interval $($ mean \pm SD $2.1 \pm 3.7$ days, median 
A

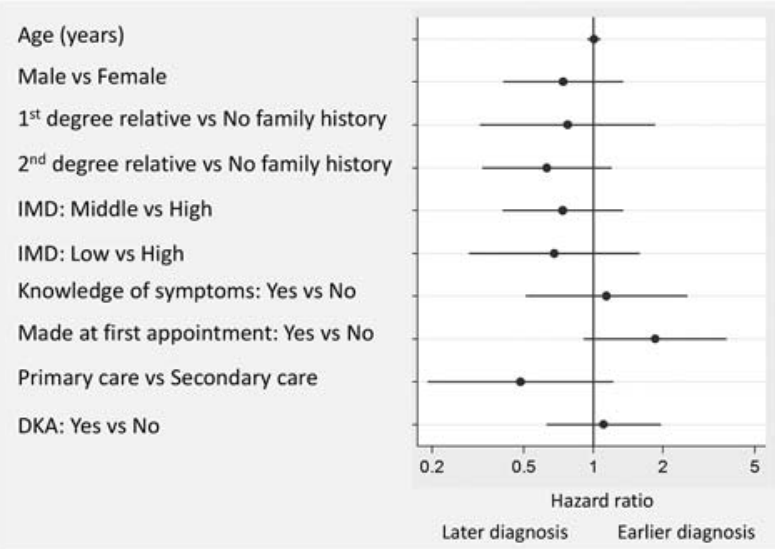

B

Age (years)

Male vs Female

$1^{\text {st }}$ degree relative vs No family history

$2^{\text {nd }}$ degree relative vs No family history

IMD: Middle vs High

IMD: Low vs High

Knowledge of symptoms: Yes vs No

Considered diabetes: Yes vs No

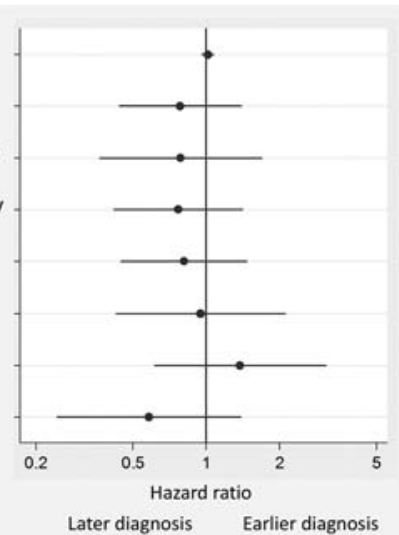

C

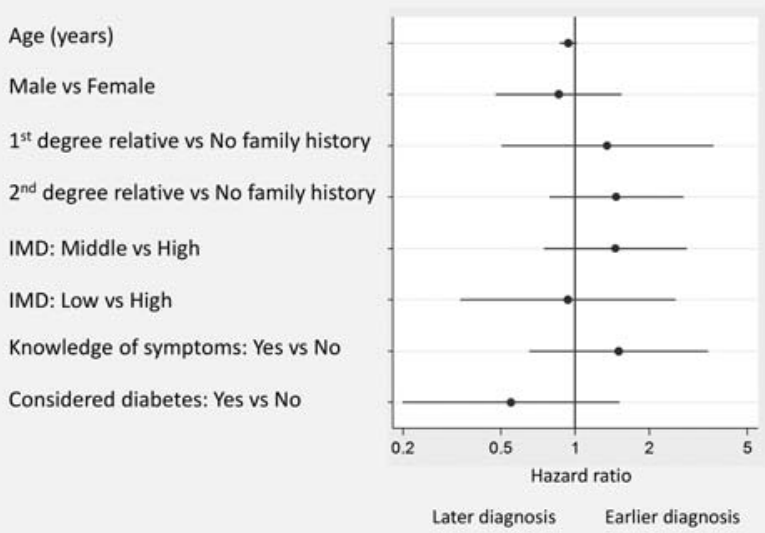

Figure 1 Associations between parent/child characteristics and (A) the total diagnostic interval, (B) the appraisal interval and $(\mathrm{C})$ the help-seeking interval. HRs adjusted for all variables in each figure. Cox model in (A) stratified by whether parents suspected the diagnosis or not. DKA, diabetic ketoacidosis; IMD, index of multiple deprivation.

(IQR) 0 (0-3) days) rather than the scheduling interval $($ mean \pm SD $1.1 \pm 2.6$ days, median (IQR) $0(0-1)$ days).

Cox-regression analysis (figure 1C) showed no significant associations between parent/child characteristics and the help-seeking interval.

The most common reasons that parents cited for seeking medical advice sooner rather than later (table 5 ) were that the symptoms were not getting better or were getting worse, wanting reassurance or concern
Table 3 Duration of diagnostic intervals

\begin{tabular}{lccl}
\hline & $\begin{array}{l}\text { Mean } \pm \text { SD } \\
\text { (days) }\end{array}$ & $\begin{array}{l}\text { Median (IQR) } \\
\text { (days) }\end{array}$ & $\mathbf{n}$ \\
\hline Appraisal interval & $41 \pm 51.7$ & $20(9,40)$ & 75 \\
Help-seeking interval & $3 \pm 4.6$ & $1(0,4.5)$ & 83 \\
Diagnostic interval & $5 \pm 34.8$ & $0(0,0)$ & 83 \\
Total diagnostic interval & $48 \pm 60.4$ & $25(14,50)$ & 74 \\
\hline
\end{tabular}

something serious was wrong. This was also reflected in the free text responses where $22 \%$ of parents noted that worsening or persistent symptoms was the reason they decided to seek help. In general, fewer parents reported factors that led to them seeking medical advice later. Of those that did, the most common reason for waiting was hope that the symptoms would go away $(51.6 \%)$ but $29.8 \%$ felt difficulty getting an appointment contributed and $27.6 \%$ and $25.2 \%$ were worried about wasting the GPs time or that the GP would not take them seriously, respectively.

\section{The diagnostic interval}

The diagnostic interval was the shortest of the intervals with a mean $\pm \mathrm{SD}$ of 5 days \pm 34.8 and median 0 (IQR; $0-0)$ days. Sixty-nine $(78 \%)$ children were diagnosed at first consultation. Cox regression was not possible given the high number of children with a diagnostic interval of zero. However, children whose parents suspected the diagnosis $(\mathrm{n}=61,70.1 \%)$ were more likely (unadjusted relative risk (RR) $1.30,1.02$ to $1.67, \mathrm{p}=0.046$ ) to be diagnosed at first consultation $(\mathrm{n}=52,85.2 \%)$ than those in whom there was no suspicion $(\mathrm{n}=26,29.9 \%$ with 17 (65.4\%) diagnosed at first consultation). All children (10) who were seen first in secondary care were diagnosed at first consultation compared with $76.6 \%$ (59/ 77 ) of those seen first in primary care, but this difference was not statistically significant $(p=0.114)$. None of the variables considered were significantly associated with risk of DKA (figure 2).

Further details from the questionnaires were available from 14 of the 18 children who were not diagnosed at first encounter with primary care. Of these, six had fasting glucose blood tests arranged by the GP and four were given alternative diagnoses (urine infection, viral infection, tonsillitis, puberty) and diagnosed at a second appointment. Two children were diagnosed with psychological problems: In one case the child's mother had seen the GP alone to discuss her child's 'obsessive drinking' and was advised to see the school counsellor, and in the second the GP apparently felt the symptoms were psychological and the child was diagnosed in the emergency department four consultations later. One other family had already performed a finger prick glucose test at home which was high but the GP did not trust the result and asked the child to come back later in the day with a urine sample. In the final case, the child's mother had spoken to a health visitor and suggested diabetes 
Table 4 Parents' explanations for the 10 most common symptoms

\begin{tabular}{|c|c|c|c|c|}
\hline \multirow{2}{*}{$\frac{\text { Symptom }}{\text { Polydipsia }}$} & \multirow{2}{*}{$\frac{n}{85}$} & \multirow{2}{*}{$\begin{array}{l}\text { Number with explanation } \\
\text { for symptom } \\
\text { n (\%) } \\
58(68.2)\end{array}$} & \multicolumn{2}{|c|}{$\begin{array}{l}\text { Most common explanations } \\
\mathbf{n}(\%)\end{array}$} \\
\hline & & & Hot weather & 19 (32.8) \\
\hline & & & Infection & $13(22.4)$ \\
\hline & & & Activity/travel & $10(17.2)$ \\
\hline \multirow{3}{*}{ Polyuria } & 73 & $47(64.4)$ & Drinking more & $29(61.7)$ \\
\hline & & & Urine infection & $6(12.7)$ \\
\hline & & & Diabetes & $4(8.5)$ \\
\hline \multirow[t]{3}{*}{ Tiredness } & 66 & $44(66.7)$ & School related & $12(27.3)$ \\
\hline & & & Infection & $5(11.9)$ \\
\hline & & & Nocturia & $4(9.5)$ \\
\hline \multirow[t]{3}{*}{ Nocturia } & 64 & $40(62.5)$ & Drinking more & $26(65.0)$ \\
\hline & & & Diabetes & $4(10.0)$ \\
\hline & & & Urine infection & $3(7.5)$ \\
\hline \multirow[t]{3}{*}{ Weight loss } & 56 & 33 (58.9) & Growth related & $15(45.5)$ \\
\hline & & & Decreased appetite & $4(12.1)$ \\
\hline & & & Increased activity & $3(9.1)$ \\
\hline \multirow{3}{*}{ Changes in behaviour/mood } & 48 & $31(64.6)$ & Tiredness & $10(32.3)$ \\
\hline & & & Age related/puberty & $7(22.6)$ \\
\hline & & & Infection/illness & $6(19.4)$ \\
\hline \multirow[t]{3}{*}{ Change in appetite } & 45 & $28(62.2)$ & Growth related & $14(50.0)$ \\
\hline & & & Infection & $5(17.9)$ \\
\hline & & & Holiday related & $2(7.1)$ \\
\hline \multirow{3}{*}{ Abdominal pain } & 37 & $19(51.4)$ & Infection & $4(21.1)$ \\
\hline & & & School related & $3(15.8)$ \\
\hline & & & Period pains & $3(15.8)$ \\
\hline \multirow[t]{3}{*}{ Nocturnal enuresis } & 33 & $23(69.7)$ & Drinking more & $13(56.5)$ \\
\hline & & & Tired & $4(17.4)$ \\
\hline & & & School related & $3(13.0)$ \\
\hline \multirow[t]{3}{*}{ Different smelling breath } & 31 & $14(45.2)$ & Poor dental hygiene & $4(28.6)$ \\
\hline & & & Infection & $3(21.4)$ \\
\hline & & & Diabetes & $3(21.4)$ \\
\hline
\end{tabular}

but was told "no, not unless the child is lifeless". The mother took the child to the GP 12 days later and the diagnosis was made at that consultation.

\section{DISCUSSION \\ Principal findings}

This study shows that all children with new onset T1D present with one, and $98 \%$ present with two, of the four main symptoms of diabetes (polydipsia, polyuria, weight loss and tiredness). Moreover, over half have had symptoms for over 3 weeks before diagnosis. Most of that time is the appraisal interval during which parents found alternative explanations for the symptoms, discussed the symptoms with family and friends and looked on the internet for information. Once they made the decision to seek advice, access to healthcare was generally not difficult with $28 \%$ consulting with a healthcare professional on the same day. However, when asked about factors contributing to their decision to seek help, nearly a third of parents felt that difficulty getting an appointment contributed to them waiting to seek help and over a quarter felt that worry about wasting the doctor's time influenced their decision. This suggests that even if access is not difficult, it is perceived as such.

Once parents had sought help, one in five children were then not diagnosed at their first consultation with a healthcare professional, mainly due to being given an alternative diagnosis, most commonly infection, or waiting for further investigations. Diagnosis at first consultation was associated with a shorter total diagnostic interval and children were more likely to be diagnosed at first consultation when their parents suspected the diagnosis of T1D. The association between diagnosis at first consultation and total diagnostic interval may simply reflect the additional time between consultations, or it may be due to biological differences causing some children to develop symptoms more slowly which are then more difficult for parents as well as primary care physicians to recognise.

\section{Strengths and weaknesses}

By using a questionnaire developed from a previous interview study ${ }^{14}$ and the Model of Pathway to Treatment ${ }^{16 \quad 17}$ as a framework for analysis, this study 
Table 5 Factors influencing parents' decisions to seek medical advice sooner or later

\begin{tabular}{|c|c|c|c|c|c|}
\hline Factors influencing seeking medical advice & $\begin{array}{l}\text { Not at all } \\
n(\%)\end{array}$ & $\begin{array}{l}\text { A little } \\
\text { n (\%) }\end{array}$ & $\begin{array}{l}\text { Quite a lot } \\
\text { n (\%) }\end{array}$ & $\begin{array}{l}\text { Very much } \\
\text { n (\%) }\end{array}$ & $\begin{array}{l}\text { Did not answer } \\
\text { n (\%) }\end{array}$ \\
\hline \multicolumn{6}{|l|}{ Sooner } \\
\hline Concern something serious & $9(10.3)$ & $16(18.4)$ & $18(20.7)$ & $42(48.3)$ & $2(2.3)$ \\
\hline Symptoms getting worse & $7(8.0)$ & $19(21.8)$ & $14(16.1)$ & $46(52.9)$ & $1(1.1)$ \\
\hline Symptoms not getting better & $4(4.6)$ & $12(13.8)$ & $22(25.3)$ & $45(51.7)$ & $4(4.6)$ \\
\hline Wanting reassurance & $8(9.2)$ & $15(17.2)$ & $16(18.4)$ & $46(52.9)$ & $2(2.3)$ \\
\hline Comments from family & $30(34.5)$ & 28 (32.2) & $11(12.6)$ & $13(14.9)$ & $5(5.7)$ \\
\hline Comments from school & $63(72.4)$ & $10(11.5)$ & $4(4.6)$ & $4(4.6)$ & $6(6.9)$ \\
\hline Comments from friends & 49 (56.3) & $20(23.0)$ & $7(8.0)$ & $5(5.7)$ & $6(6.9)$ \\
\hline Written information & $50(57.5)$ & $8(9.2)$ & $10(11.5)$ & $15(17.2)$ & $4(4.6)$ \\
\hline \multicolumn{6}{|l|}{ Later } \\
\hline Difficulty getting appointment & $60(69.0)$ & $8(9.2)$ & $7(8.0)$ & $11(12.6)$ & $1(1.1)$ \\
\hline Waiting for a particular doctor or nurse & $68(78.2)$ & $7(8.0)$ & $4(4.6)$ & $6(6.9)$ & $2(2.3)$ \\
\hline Concern about having to wait at the surgery & $72(82.8)$ & $6(6.9)$ & $4(4.6)$ & $3(3.4)$ & $2(2.3)$ \\
\hline Worry about wasting the doctor's or nurse's time & $61(70.1)$ & $10(11.5)$ & $8(9.2)$ & $6(6.9)$ & $2(2.3)$ \\
\hline Worry the doctor would not take them seriously & $62(71.3)$ & $12(13.8)$ & $3(3.4)$ & $7(8.0)$ & $3(3.4)$ \\
\hline Symptoms were not very serious & $55(63.2)$ & $20(23.0)$ & $9(10.3)$ & $0(0)$ & $3(3.4)$ \\
\hline Hope the symptoms would go away & $42(48.3)$ & $21(24.1)$ & $9(10.3)$ & $15(17.2)$ & $0(0)$ \\
\hline Fear of serious diagnosis & $58(66.7)$ & $16(18.4)$ & $5(5.7)$ & $7(8.0)$ & $1(1.1)$ \\
\hline
\end{tabular}

provides in-depth insights into the diagnostic pathway of children with newly diagnosed T1D and allows factors acting at different stages in the pathway to be explored.

The main weakness is that the data were necessarily collected retrospectively and so are subject to recall and framing bias. Parents have multiple contacts with different healthcare professionals in the period immediately following diagnosis and so their responses to the questionnaire reflect a post hoc rationalisation of events framed by those subsequent encounters and increased knowledge since the diagnosis. The inclusion of a calendar with key events in the questionnaires minimised the error in recall of dates, and the free text responses allowed internal validation and checking of prompted responses. Despite

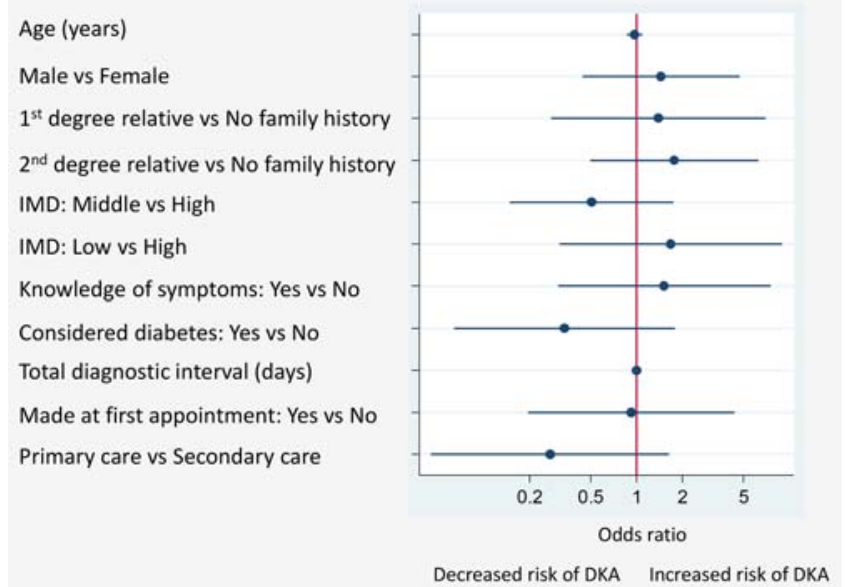

Figure 2 Associations between parent/child characteristics and presence/absence of DKA. ORs adjusted for all variables in the figure. DKA, diabetic ketoacidosis; IMD, index of multiple deprivation. these efforts, we still only have the parents' perspective on the pathway and were not able to confirm the number of healthcare contacts, diagnostic tests or the parental reports of missed opportunities for diagnosis. We were, however, able to confirm the diagnosis of DKA from clinical records and, although there was variation in the definition of DKA used across the 11 sites, all included a biochemical measurement of either $\mathrm{pH}$ or bicarbonate.

Our results are also based on the views of 88 parents. Although not a large number, they were recruited from 11 sites across a large region of the UK and the response rate was over $50 \%$ with no significant differences in gender, age or DKA status between the children whose parents responded and those who did not. The fact that they were a predominantly white group from less deprived areas of England limits the generalisability of the results outside the East of England but the main findings are likely to be relevant across the UK and other countries with similar primary care healthcare provision. The questionnaire also did not include questions specifically for the children to complete and so we are unable to comment on the views of the children during this time.

\section{Comparison with existing literature}

The median duration of symptoms prior to diagnosis was 13-17 days for the nine most frequent symptoms, with a mean of 30-50 days. This is longer than previous studies relying on retrospective review of medical records ${ }^{20-23}$ but similar to studies which have used a checklist to identify subtle symptoms ${ }^{24}$ or asked parents soon after diagnosis. ${ }^{13} 14$ The wide range (a few days to over 6 months) has been described previously ${ }^{14} 21 \quad 23$ and highlights the heterogeneous nature of the disease. 
The frequency of individual symptoms we report is also similar to previous studies. ${ }^{13} 14202225$ Additionally, we showed that all the children had at least one of four symptoms (polydipsia, polyuria, weight loss and fatigue) and over half $(50.6 \%)$ had all four. Consistent with the known course of the disease and previous studies, vomiting, ${ }^{22} 24$ weight loss ${ }^{132526}$ and dyspnoea ${ }^{22}$ were more common in those children who presented with DKA.

This is the first quantitative study to compare the time periods during the pathway to diagnosis of T1D in children. The finding that most of the total diagnostic interval was the appraisal interval is consistent with a previous qualitative study ${ }^{14}$ and the free text analysis confirms that during that time the parents find alternative explanations for the symptoms initially and make use of a social network of extended family, friends and work colleagues, or the internet. ${ }^{14} 2728$ The findings that children were more likely to be diagnosed at their first encounter with a healthcare professional when their parents suspected diabetes prior to that consultation may also reflect the findings of previous qualitative work in which a number of parents prompted the GP to consider T1D and pushed for investigations. ${ }^{14}$ However, while parental suspicion of T1D has also been shown to be associated with a reduced risk of DKA in a parental survey, ${ }^{13}$ in that study the incidence of DKA at presentation was no different whether or not the parents discussed their concerns with the healthcare professional, suggesting other factors may be contributing. The absence of an effect of parental prior knowledge of diabetes either on the total diagnostic interval or the risk of DKA further highlights the complexities around the role of knowledge on help-seeking behaviour.

The finding that parents worry about wasting the doctor's time has also been shown in previous qualitative studies in children ${ }^{29} 30$ and in studies of help-seeking behaviour for adults with symptoms of cancer in the $\mathrm{UK}^{31} 32$ and so it may reflect a particular British trait rather than be specific to T1D or children.

\section{Implications for clinicians and policymakers}

Clinicians should remain alert to the possibility of T1D in all children presenting with one or more symptoms of polyuria, polydipsia, weight loss and tiredness-as almost all children have at least two of these. Interventions targeted at increasing public awareness, such as the 4 T's campaign launched by Diabetes UK to raise awareness of the four most common symptoms of T1D (Toilet, Thirsty, Tired and Thinner), ${ }^{33}$ should continue to focus on these established symptoms.

As most of the time between symptom onset and diagnosis is the appraisal interval, the greatest benefit is likely to be seen from interventions directed towards parents and their social network, probably via the internet. Despite ongoing government pressure for better access to primary care, improving access is unlikely to have much impact on the pathway. Instead efforts should be made to address the perception that access is difficult and the general concern in the UK about wasting healthcare professional time, particularly for children with acute or sub-acute health concerns.

Additionally, although the diagnostic interval itself was generally short, one in five children presenting to primary care were not diagnosed at first consultation. Similar numbers have been reported in a recent survey in the UK which found that $24 \%$ were not diagnosed at first contact with a healthcare professional, ${ }^{13}$ and studies in the USA, Canada and Poland noted between $14 \%$ and $35 \%$ of children had more than one consultation before diagnosis. ${ }^{6} 734-36$ As in those studies, the most common reasons for not being diagnosed at first encounter was either being given an alternative diagnosis, most commonly infection, or waiting for further investigations. In this study $33 \%$ of those not diagnosed at first consultation were waiting for fasting glucose tests and in other studies the number waiting for further investigations is as high as $46 \% .{ }^{6}{ }^{13}$ This suggests that healthcare professionals may have considered a diagnosis of T1D but either lack ready access to rapid tests to confirm or exclude the diagnosis, or are reluctant to use existing tests in children. ${ }^{14}$ Access to point of care urine and finger-prick testing and the use of those tests should be routine management for all children presenting with one or more of the four main symptoms of diabetes. The increased use of point of care testing in emergency departments may also explain why all children seen in secondary care were diagnosed at their first consultation. While educational interventions aimed at primary care physicians may help a small number of children not currently diagnosed at first encounter, finding ways to overcome barriers to point-of-care tests in primary care may be more effective and this approach may also improve the diagnosis of other serious illnesses in children and adults.

\section{Unanswered questions and future research}

While this study contributes to our understanding of the pathway to diagnosis and the stages at which this may be improved, the findings are unable to explain the large variability in the overall duration of the pathway to diagnosis and why some children develop DKA within a few weeks while others can be symptomatic for up to 6 months before requiring treatment. Further studies are, therefore, needed into the natural course and biology of the disease to better understand these variations. The findings also highlight the need for continuing research into the presentation of serious but rare conditions in primary care and the best ways to improve diagnosis of these conditions.

\section{Author affiliations}

${ }^{1}$ The Primary Care Unit, University of Cambridge, Cambridge, UK

${ }^{2}$ Department of Family Medicine, University of Washington, Seattle, Washington, USA

${ }^{3}$ Cambridge University Hospitals NHS Foundation Trust, Cambridge, UK 
${ }^{4}$ MRC Epidemiology Unit, University of Cambridge, Institute of Metabolic Science, Cambridge, UK

Acknowledgements The authors thank all the parents who kindly gave up their time and shared their personal stories with us to either help develop the questionnaire or take part in the study. They also thank the Paediatric diabetes clinical teams at the 11 hospitals, particularly Jon Hassler-Hurst (Ipswich), Holly Roper (Norfolk and Norwich), Elissa Harwood (Cambridgeshire community services), Nazia Bhatti and Claire Pesterfield (Addenbrooke's hospital NHS foundation trust), Julia Harding and Jacky Plumb (West Suffolk), Philippa Corbishley and Laura Ardrey (QE2 and Lister), Suzie Williams (SEPT), Mandy Stevenson (Harlow), Claire Gibbs and Allyson Davison (James Paget) and Meeta Patel (Luton and Dunstable). They are also grateful to the Diabetes Research Network and the East of England Children and Young People's Diabetes Network and network manager Kate Wilson for support, James Brimicombe for advice on data management, Dr Carlo Acerini for comments on the questionnaire and final manuscript and support through his role as Chair of the East of England Children and Young People's Diabetes Network, Professor Jon Emery for comments on the questionnaire, and Professor David Dunger for his support and encouragement throughout the study and comments on the final manuscript.

Contributors JAU-S, MJT, FMW and SJS were involved in the design of the study and all authors were involved in analysis of the data. JAU-S and FMW developed the questionnaire. JAU-S wrote the first draft of the manuscript and all authors reviewed and edited the manuscript.

Funding The study was funded by the Royal College of General Practitioners Scientific Foundation Board (SFB-2011-15). JAU-S was supported by a National Institute of Health Research (NIHR) Academic Clinical Fellowship and subsequently Clinical Lectureship, and FMW by an NIHR Clinician Scientist award. SJS was supported by the Medical Research Council http://www.mrc. ac.uk (Unit Programme number MC UU 12015/1). The views expressed in this publication are those of the author(s) and not necessarily those of the NHS, the NIHR or the Department of Health. All researchers were independent of the funding body (although FMW subsequently became a member of the Royal College of General Practitioners Scientific Foundation Board), and the study sponsors and funder had no role in study design; data collection, analysis and interpretation of data; in the writing of the report; or decision to submit the article for publication.

Competing interests None.

Ethics approval The study obtained ethical approval from the East of England Hertfordshire REC (reference number 12/EE/0390).

Provenance and peer review Not commissioned; externally peer reviewed.

Data sharing statement The questionnaire is available from the corresponding author on request.

Open Access This is an Open Access article distributed in accordance with the terms of the Creative Commons Attribution (CC BY 4.0) license, which permits others to distribute, remix, adapt and build upon this work, for commercial use, provided the original work is properly cited. See: http:// creativecommons.org/licenses/by/4.0/

\section{REFERENCES}

1. Lawrence JM, Imperatore G, Dabelea D, et al. Trends in incidence of type 1 diabetes among non-Hispanic white youth in the U.S. 2002-2009. Diabetes 2014;63:3938-45.

2. Fazeli Farsani S, Souverein PC, van der Vorst MMJ, et al. Increasing trends in the incidence and prevalence rates of type 1 diabetes among children and adolescents in the Netherlands. Pediatr Diabetes 2014. doi:10.1111/pedi.12232 [Epub ahead of print 7 Nov 2014].

3. Usher-Smith JA, Thompson MJ, Sharp SJ, et al. Factors associated with the presence of diabetic ketoacidosis at diagnosis of diabetes in children and young adults: a systematic review. BMJ 2011;343:d4092.

4. Blanc N, Lucidarme N, Tubiana-Rufi N. Factors associated to ketoacidosis at diagnosis of type 1 diabetes in children. Arch Pediatr 2003;10:320-5.

5. Hamilton DV, Mundia SS, Lister J. Mode of presentation of juvenile diabetes. BMJ 1976;2:211-12.
6. Mallare JT, Cordice CC, Ryan BA, et al. Identifying risk factors for the development of diabetic ketoacidosis in new onset type 1 diabetes mellitus. Clin Pediatr (Phila) 2003;42:591-7.

7. Pawłowicz M, Birkholz D, Niedźwiecki $M$, et al. Difficulties or mistakes in diagnosing type 1 diabetes mellitus in children? The consequences of delayed diagnosis. Pediatr Endocrinol Diabetes Metab 2008;14:7-12.

8. Soliman AT, EIZalabany MM, Bappal B, et al. Permanent neonatal diabetes mellitus: epidemiology, mode of presentation, pathogenesis and growth. Indian J Pediatr 1999;66:363-73.

9. Usher-Smith JA, Thompson M, Ercole A, et al. Variation between countries in the frequency of diabetic ketoacidosis at first presentation of type 1 diabetes in children: a systematic review. Diabetologia 2012;55:2878-94

10. Abdul-Rasoul M, Habib H, Al-Khouly M. "The honeymoon phase" in children with type 1 diabetes mellitus: frequency, duration, and influential factors. Pediatr Diabetes 2006;7:101-7.

11. Bowden SA, Duck MM, Hoffman RP. Young children ( $<5 \mathrm{yr}$ ) and adolescents ( $>12 \mathrm{yr}$ ) with type 1 diabetes mellitus have low rate of partial remission: diabetic ketoacidosis is an important risk factor. Pediatr Diabetes 2008;9:197-201.

12. Fredheim $\mathrm{S}$, Johannesen $\mathrm{J}$, Johansen $\mathrm{A}$, et al. Diabetic ketoacidosis at the onset of type 1 diabetes is associated with future $\mathrm{HbA1c}$ levels. Diabetologia 2013;56:995-1003.

13. Lokulo-Sodipe $\mathrm{K}$, Moon RJ, Edge $\mathrm{J}$ a, et al. Identifying targets to reduce the incidence of diabetic ketoacidosis at diagnosis of type 1 diabetes in the UK. Arch Dis Child 2014;99:438-42.

14. Usher-Smith JA, Thompson MJ, Walter FM. "Looking for the needle in the haystack": a qualitative study of the pathway to diagnosis of type 1 diabetes in children. BMJ Open 2013;3:e004068

15. English Indices of Deprivation 2010. https://www.gov.uk/government/ publications/english-indices-of-deprivation-2010 (accessed 7 Feb 2014).

16. Walter F, Webster A, Scott S, et al. The Andersen model of total patient delay: a systematic review of its application in cancer diagnosis. J Health Serv Res Policy 2012;17:110-18.

17. Scott SE, Walter FM, Webster A, et al. The model of pathways to treatment: conceptualization and integration with existing theory. $\mathrm{Br}$ Health Psychol 2013;18:45-65.

18. Andersen BL, Cacioppo JT. Delay in seeking a cancer diagnosis: delay stages and psychophysiological comparison processes. $\mathrm{Br} \mathrm{J}$ Soc Psychol 1995;34:33-52.

19. Allgar VL, Neal RD. Delays in the diagnosis of six cancers: analysis of data from the National Survey of NHS Patients: cancer. $\mathrm{Br} J$ Cancer 2005;92:1959-70.

20. Neu A, Willasch A, Ehehalt S, et al. Ketoacidosis at onset of type 1 diabetes mellitus in children-frequency and clinical presentation Pediatr Diabetes 2003:4:77-81.

21. Roche EF, Menon A, Gill D, et al. Clinical presentation of type 1 diabetes. Pediatr Diabetes 2005;6:75-8

22. Xin $\mathrm{Y}$, Yang $\mathrm{M}$, Chen $\mathrm{XJ}$, et al. Clinical features at the onset of childhood type 1 diabetes mellitus in Shenyang, China. J Paediatr Child Health 2010;46:171-5.

23. Neu A, Ehehalt S, Willasch A, et al. Varying clinical presentations at onset of type 1 diabetes mellitus in children-epidemiological evidence for different subtypes of the disease? Pediatr Diabetes 2001;2:157-3.

24. Ting $\mathrm{WH}$, Huang CY, Lo FS, et al. Clinical and laboratory characteristics of type 1 diabetes in children and adolescents: experience from a medical center. Acta Paediatr Taiwanica 2007;48:119-24.

25. Kapellen TM, Galler A, Nietzschmann U, et al. Prevalence of diabetic ketoacidosis in newly diagnosed children and adolescents with type 1 diabetes mellitus. Experience of a center for pediatric diabetology in Germany [Article in German]. Monatsschr Kinderheilkd 2001;149:679-82.

26. Lévy-Marchal C, Patterson CC, Green A. Geographical variation of presentation at diagnosis of type I diabetes in children: the EURODIAB study. Diabetologia 2001;44:B75-80.

27. Neill SJ. Acute childhood illness at home: the parents' perspective. J Adv Nurs 2000;31:821-32.

28. Kai J. What worries parents when their preschool children are acutely ill, and why: a qualitative study. BMJ 1996;313:983-6.

29. Dixon-Woods M, Findlay M, Young B, et al. Parents' accounts of obtaining a diagnosis of childhood cancer. Lancet 2001;357:670-4.

30. Francis $\mathrm{Na}$, Crocker JC, Gamper A, et al. Missed opportunities for earlier treatment? A qualitative interview study with parents of children admitted to hospital with serious respiratory tract infections. Arch Dis Child 2011;96:154-9.

31. Forbes LJL, Atkins L, Thurnham A, et al. Breast cancer awareness and barriers to symptomatic presentation among women from different ethnic groups in East London. Br J Cancer 2011;105:1474-9. 
32. Forbes LJL, Simon AE, Warburton F, et al. Differences in cancer awareness and beliefs between Australia, Canada, Denmark, Norway, Sweden and the UK (the International Cancer Benchmarking Partnership): do they contribute to differences in cancer survival? Br J Cancer 2013;108:292-300.

33. Diabetes UK. 4 T's campaign. https://www.diabetes.org.uk/Get involved/Campaigning/Our-campaigns/4-Ts-campaign/ (accessed 19 Aug 2014).
34. Bui $\mathrm{H}$, To $\mathrm{T}$, Stein $\mathrm{R}$, et al. Is diabetic ketoacidosis at disease onset a result of missed diagnosis? J Pediatr 2010;156:472-7.

35. Quinn M, Fleischman A, Rosner B, et al. Characteristics at diagnosis of type 1 diabetes in children younger than 6 years. $J$ Pediatr 2006;148:366-71.

36. Pawlowicz M, Birkholz D, Niedzwiecki M, et al. Difficulties or mistakes in diagnosing type 1 diabetes in children?-demographic factors influencing delayed diagnosis. Pediatr Diabetes 2009;10:542-9. 